\title{
Comparison between Primary and Secondary Tracheoesophageal Puncture Prosthesis: A Systematic Review
}

\author{
José Carlos Barauna Neto ${ }^{a} \quad$ Rogério Aparecido Dedivitis ${ }^{b}$ \\ Felipe Toyama Aires ${ }^{b}$ Robert Zasawadzki Pfann ${ }^{c}$ \\ Leandro Luongo Matos $^{b}$ Claudio Roberto Cerneab \\ a Palmas Oncologic Center, Palmas, ${ }^{b}$ Department of Head and Neck Surgery, \\ University of São Paulo School of Medicine, and ' University of São Paulo School of \\ Medicine, São Paulo, Brazil
}

\section{Keywords}

Laryngectomy · Laryngeal prosthesis · Carcinoma - Squamous cell · Complications ·

Rehabilitation · Meta-analysis · Systematic review

\begin{abstract}
Introduction: Since the introduction of tracheoesophageal puncture (TEP) and placement of voice prosthesis, this has become the method of choice to achieve speech rehabilitation after total laryngectomy. Objective: To compare the complications and success in speech rehabilitation of patients undergoing rehabilitation after primary and secondary TEP (TEP1 and TEP2) through a systematic review. Methods: The literature survey included research in MedLine, Scielo, Lilacs, Cochrane and Websco until June 2016. Results: The rate of leakage around the prosthesis was higher in TEP1 (22.5 vs. $6.9 \%, p=0.03)$. There were higher rates of wound infection (9.1 vs. $3.9 \%$ ) and tracheal stenosis ( 8.5 vs. $4.5 \%$ ) in the TEP1 group compared to TEP2, however with no statistical significance. The evaluation of speech quality was not possible due to the heterogeneity of the studies. Conclusion: There is a reduction in the risk of leakage around the prosthesis among TEP2 patients.

(c) 2017 S. Karger AG, Basel
\end{abstract}

\section{Introduction}

Since the first laryngectomies were performed, the loss of the natural voice has been considered a major disabling consequence of this procedure, together with changes in respiration and deglutition. For decades, mechanisms and prosthetics have been developed in an 
attempt to achieve speech rehabilitation with varying rates of success. Traditionally, rehabilitation efforts have been focused on the use of esophageal speech, tracheoesophageal puncture procedure (TEP) and electronic larynx [1].

The use of a prosthetic valve has become an important method for rehabilitation after total laryngectomy since the introduction of the Blom-Singer Duckbill $[2,3]$ and Panje prostheses [4]. TEP is an acceptable method of voice restoration, with better acquisition in speech intelligibility and fluency. Many aids have been developed since then for primary TEP performed at the same time as the laryngectomy or as a secondary procedure (secondary TEP) at a later stage. The problems found during the routine use of TEP are connected to the high air flow resistance of the prosthesis and the useful life of the prosthesis. The development of low resistance has facilitated prosthetic adaptation. Myotomy of the pharyngeal constrictor muscles, in turn, reduces the pressure in the neopharynx, thus facilitating the airflow. Colonization by fungi and fistula mobility can cause valve dysfunction. The use of local antifungal drugs has been shown to extend the life of the prosthesis [5].

In the 1980s, the use of a voice prosthesis became the standard for speech rehabilitation in patients undergoing total laryngectomy. Rehabilitation with esophageal speech has a success rate between 24 and 32\%, whereas those rates may increase to $94 \%$ for immediate results for primary TEP and $64 \%$ for secondary TEP. In the long-term results after 1 year of follow-up, the success rates can range from 65 to $85 \%$ in primary TEP and from 69 to $83 \%$ in secondary TEP [6].

The advantage of placing primary TEP is that patients are not subjected to a second surgery for speech acquisition. Furthermore, patients can initiate speech rehabilitation within 2 weeks after laryngectomy. However, primary TEP is viewed as being associated with an increased risk of stoma surgical complications, such as fistula, leakage at the puncture site, stoma stenosis, and local infection. It was suggested that the complication rate could be lower if TEP was performed as a slow procedure due to better maturation of the tracheostoma. Added to this, patients with secondary TEP could have more reasonable expectations regarding voice quality, and therefore be more satisfied with their voices after the postoperative voiceless period [7]. Primary TEP avoids the need for a second operation with earlier voice restoration and faster acquisition of fluent speech. However, there is still controversy about the most appropriate time for the procedure and the differences in the vocal outcome and complication rates related to it [8], since primary TEP could present a higher rate of complication. Thus, the aim of this systematic review is to compare the outcome of primary versus secondary TEP.

\section{Methods}

Identification and Selection of the Studies

A literature survey strategy was employed in order to perform a systematic review of the available evidence. This included research into the electronic database Medline in Pubmed (www.ncbi.nlm.nih.gov/ pubmed), Scielo, Lilacs, Cochrane and Websco until June 2016, using the search strategy with the key words "laryngectomy AND tracheoesophageal puncture OR punctures," "laryngeal neoplasms OR laryngectomy AND pharyngocutaneous fistula OR cutaneous fistula" in PubMed and EMBASE; and "neoplasias laríngeas OR laringectomia AND fistula cutânea" in MedLine. References of the selected studies to screen material not found in the electronic searches were also consulted through manual search.

\section{Inclusion and Exclusion Criteria}

The series were composed of patients who underwent total laryngectomy or pharyngolaryngectomy. The interventions analyzed were primary and secondary TEP techniques, focusing on complications and speech rehabilitation. 
Barauna Neto et al.: Comparison between Primary and Secondary Tracheoesophageal Puncture Prosthesis: A Systematic Review

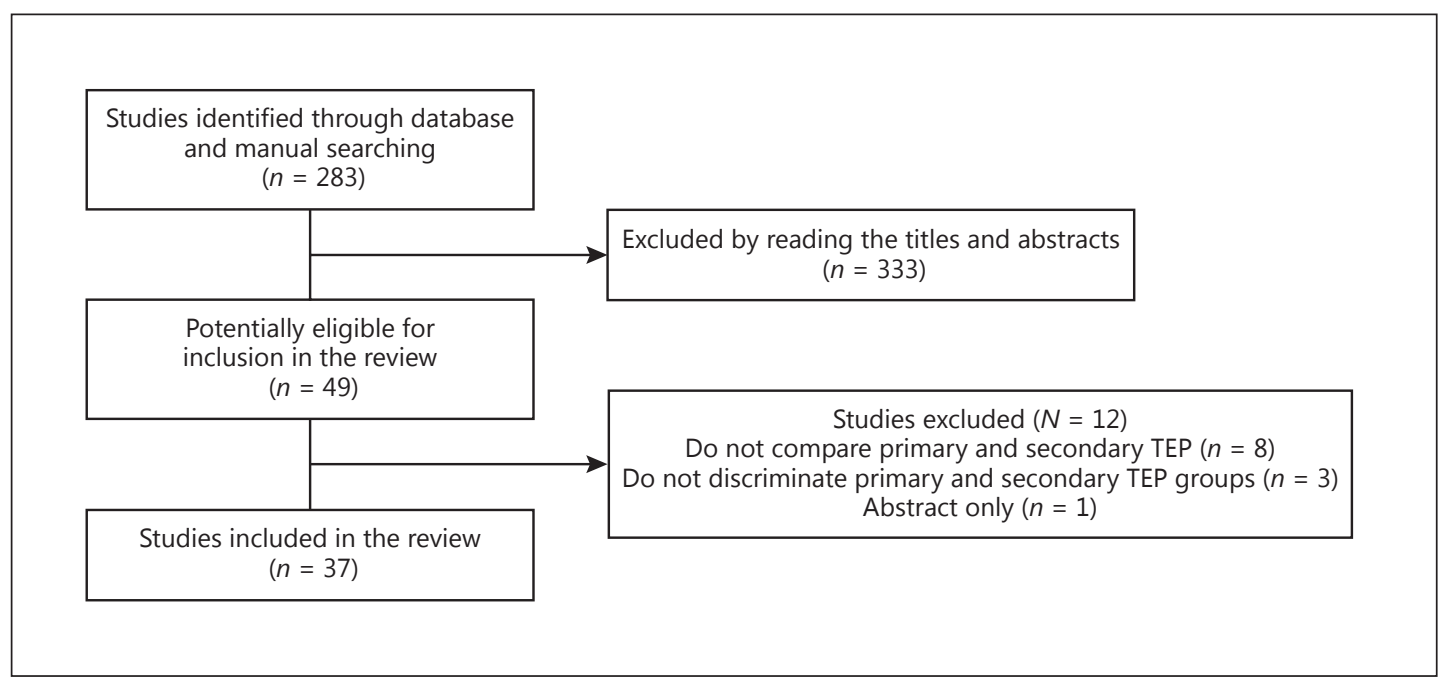

Fig. 1. Flowchart of the evaluated articles.

\section{Outcome Evaluation}

The primary outcomes analyzed were complications and speech rehabilitation.

\section{Evidence Level and Methodological Quality}

The quality of the selected studies was analyzed in detail in order to evaluate the strength of their evidence and the validity of their inclusion in our paper. The classification of the recommendation grade, which corresponds to the scientific strength of the study, was based on the National Health Service Center for Evidence-Based Medicine.

\section{Statistical Analysis}

The measures of effectiveness or damage expressed through absolute values were analyzed by means of absolute risk reduction (with 95\% confidence interval). The number-needed-to-treat (NNT) values and the number-needed-to-harm values were calculated for all statistically significant results. The continuous data were analyzed regarding their averages and standard deviations. The difference between the weighted averages of the groups was employed for the analysis.

\section{Results}

A total of 382 studies were found through the search strategy in the primary database used. After reading all their titles and abstracts, 37 potentially eligible articles were selected for inclusion in the review (Fig. 1).

\section{Infection}

The overall incidence of postoperative infectious processes in patients who underwent total laryngectomy was $6.9 \%$. Of these, 16 cases occurred in the TEP1 group and 5 in the TEP2 group. There was a higher incidence of infection in patients undergoing primary TEP, but with no statistically significant difference $\left(95 \% \mathrm{CI}-0.01\right.$ to $0.11 ; p=0.12 ; I^{2}=0 \%$, Fig. 2$)$.

\section{Tracheal Stenosis after Tracheostomy}

Among the primary studies, 6 analyzed the incidence of stenosis as the outcome in the postoperative period. There was a higher incidence of tracheostomy stenosis in patients 


\begin{tabular}{|c|c|c|c|c|c|c|c|}
\hline \multirow{3}{*}{$\begin{array}{l}\text { Study or subgroup } \\
\text { Boscolo-Rizzo et al., } 2008 \text { [14] }\end{array}$} & \multicolumn{2}{|c|}{ Primary } & \multicolumn{3}{|c|}{ Secondary } & \multirow{2}{*}{$\begin{array}{l}\text { Risk difference } \\
\text { M-H, random, } \\
95 \% \text { CI }\end{array}$} & \multirow{2}{*}{$\begin{array}{l}\text { Risk difference } \\
\text { M-H, random, } \\
95 \% \text { CI }\end{array}$} \\
\hline & events & total & events & total & $\begin{array}{l}\text { weight, } \\
\%\end{array}$ & & \\
\hline & 6 & 75 & 1 & 18 & 25.5 & $0.02(-0.10,0.15)$ & \\
\hline Emerick et al., 2009 [13] & 3 & 20 & 1 & 10 & 6.5 & $0.05(-0.19,0.29)$ & \\
\hline Maniglia et al., 1989 [11] & 4 & 33 & 2 & 62 & 26.6 & $0.09(-0.03,0.21)$ & 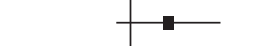 \\
\hline Morrison and Ogrady, 1986 [9] & 2 & 13 & 1 & 13 & 6.4 & $0.08(-0.17,0.32)$ & \\
\hline Shenoy et al., 2000 [12] & 0 & 15 & 0 & 8 & 12.9 & $0.00(-0.17,0.17)$ & \\
\hline Wenig et al., 1989 [10] & 1 & 20 & 0 & 18 & 22.1 & $0.05(-0.08,0.18)$ & - \\
\hline Total (95\% CI) & & 176 & & 129 & 100.0 & $0.05(-0.01,0.11)$ & \\
\hline Total events & $16(9.10$ & & $5(3.9 \%$ & & & & \\
\hline \multicolumn{7}{|c|}{ Heterogeneity: $\tau^{2}=0.00 ; \chi^{2}=0.99, \mathrm{df}=5(p=0.96) ; I^{2}=0 \%$} & $\begin{array}{lllll}-0.2 & -0.1 & 0 & 0.1 & 0.2\end{array}$ \\
\hline \multicolumn{6}{|c|}{ Test for overall effect: $\mathrm{Z}=1.56(p=0.12)$} & & Primary Secondary \\
\hline
\end{tabular}

Fig. 2. Forest plot: infection in patients undergoing primary and secondary tracheoesophageal puncture.

\begin{tabular}{|c|c|c|c|c|c|c|c|c|}
\hline \multirow{3}{*}{$\begin{array}{l}\text { Study or subgroup } \\
\text { Boscolo-Rizzo et al., } 2008 \text { [14] }\end{array}$} & \multicolumn{2}{|c|}{ Primary } & \multicolumn{3}{|c|}{ Secondary } & \multirow{2}{*}{$\begin{array}{l}\text { Risk difference } \\
\text { M-H, random, } \\
95 \% \text { CI }\end{array}$} & \multirow{2}{*}{\multicolumn{2}{|c|}{$\begin{array}{l}\text { Risk difference } \\
\text { M-H, random, } \\
95 \% \text { CI }\end{array}$}} \\
\hline & events & total & events & total & $\begin{array}{l}\text { weight, } \\
\%\end{array}$ & & & \\
\hline & 3 & 75 & 0 & 18 & 36.8 & $0.04(-0.05,0.13)$ & & + \\
\hline Cheng et al., 2006 [7] & 10 & 51 & 3 & 17 & 6.1 & $0.02(-0.19,0.23)$ & & \\
\hline Emerick et al., 2009 [13] & 0 & 20 & 0 & 10 & 14.0 & $0.00(-0.14,0.14)$ & & \\
\hline Karlen and Maisel, 2001 [15] & 3 & 33 & 3 & 63 & 22.0 & $0.04(-0.07,0.15)$ & & 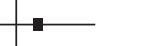 \\
\hline Shenoy et al., 2000 [12] & 1 & 15 & 0 & 8 & 6.4 & $0.07(-0.14,0.27)$ & & \\
\hline Wenig et al., 1989 [10] & 1 & 19 & 0 & 18 & 14.7 & $0.05(-0.08,0.19)$ & & $\cdot$ \\
\hline Total (95\% CI) & & 213 & & 134 & 100.0 & $0.04(-0.01,0.09)$ & & \\
\hline Total events & $18(8.5 \%$ & & $6(4.5 \%$ & & & & & \\
\hline \multicolumn{7}{|c|}{ Heterogeneity: $\tau^{2}=0.00 ; \chi^{2}=0.44, \mathrm{df}=5(p=0.99) ; I^{2}=0 \%$} & $-0.2-0.1$ & $\begin{array}{lll}1 & 1 & 1 \\
0 & 0.1 & 0.2\end{array}$ \\
\hline \multicolumn{6}{|c|}{ Test for overall effect: $\mathrm{Z}=1.41(p=0.16)$} & & Primary & Secondary \\
\hline
\end{tabular}

Fig. 3. Forest plot: stenosis tracheostomy in patients undergoing primary and secondary tracheoesophageal puncture.

undergoing primary TEP; however, with no statistically significant difference ( $95 \%$ CI -0.01 to $0.09 ; p=0.16 ; I^{2}=0 \%$, Fig. 3 ).

\section{Leakage around the Fistula}

Leakage around the fistula occurred in $13.3 \%$ in the TEP1 group and in $13.7 \%$ in the TEP2 group. There was no significant difference between groups $(95 \% \mathrm{CI}-0.15$ to $0.18 ; p=0.86$, $I^{2}=77 \%$, Fig. 4); however, this analysis shows high heterogeneity. Excluding the study related to heterogeneity from the analysis, there is a reduced risk of leakage of approximately $10 \%$ in patients undergoing secondary TEP (95\% CI 0.01-0.18; $p=0.03 ; I^{2}=0 \%$; NNT $=10$; Fig. 5).

\section{Tracheoesophageal Fistula}

This is a complication not described nor related to secondary puncture. The question is whether there would be an increase in occurrence during the primary puncture when 
Barauna Neto et al.: Comparison between Primary and Secondary Tracheoesophageal Puncture Prosthesis: A Systematic Review

\begin{tabular}{|c|c|c|c|c|c|c|c|}
\hline \multirow[t]{2}{*}{ Study or subgroup } & \multicolumn{2}{|c|}{ Primary } & \multicolumn{3}{|c|}{ Secondary } & \multirow{2}{*}{$\begin{array}{l}\text { Risk difference } \\
\text { M-H, random, } \\
95 \% \text { CI }\end{array}$} & \multirow{2}{*}{$\begin{array}{l}\text { Risk difference } \\
\text { M-H, random, } \\
95 \% \text { CI }\end{array}$} \\
\hline & events & total & events & total & $\begin{array}{l}\text { weight, } \\
\%\end{array}$ & & \\
\hline Cheng et al., 2006 [7] & 20 & 51 & 4 & 17 & 16.9 & $0.16(-0.09,0.40)$ & $\rightarrow$ \\
\hline Emerick et al., 2009 [13] & 2 & 20 & 1 & 10 & 17.7 & $0.00(-0.23,0.23)$ & \\
\hline Kao et al., 1994 [16] & 3 & 106 & 9 & 30 & 20.9 & $-0.27(-0.44,-0.10)$ & $\longrightarrow$ \\
\hline Sinclair et al., 2011 [17] & 3 & 30 & 0 & 27 & 23.3 & $0.10(-0.02,0.22)$ & - \\
\hline Wenig et al., 1989 [10] & 2 & 19 & 0 & 18 & 21.2 & $0.11(-0.06,0.27)$ & $=$ \\
\hline Total $(95 \% \mathrm{CI})$ & & 226 & & 102 & 100.0 & $0.02(-0.15,0.18)$ & \\
\hline Total events & $30(13$. & $\%)$ & $14(13.7$ & & & & \\
\hline \multicolumn{7}{|c|}{ Heterogeneity: $\tau^{2}=0.03 ; \chi^{2}=17.44, \mathrm{df}=4(p=0.002) ; I^{2}=77 \%$} & $\begin{array}{lllll}-0.5 & -0.25 & 0 & 0.25 & 0.5\end{array}$ \\
\hline \multicolumn{6}{|c|}{ Test for overall effect: $\mathrm{Z}=0.18(p=0.86)$} & & Primary Secondary \\
\hline
\end{tabular}

Fig. 4. Forest plot: leakage around the prosthesis in patients undergoing primary and secondary tracheoesophageal puncture.

\begin{tabular}{|c|c|c|c|c|c|c|c|c|}
\hline \multirow{3}{*}{$\begin{array}{l}\text { Study or subgroup } \\
\text { Cheng et al., 2006 [7] }\end{array}$} & \multicolumn{2}{|c|}{ Primary } & \multicolumn{3}{|c|}{ Secondary } & \multirow{2}{*}{$\begin{array}{l}\text { Risk difference } \\
\text { M-H, random, } \\
95 \% \text { CI }\end{array}$} & \multirow{2}{*}{\multicolumn{2}{|c|}{$\begin{array}{l}\text { Risk difference } \\
\text { M-H, random, } \\
95 \% \text { CI }\end{array}$}} \\
\hline & events & total & events & total & $\begin{array}{l}\text { weight, } \\
\%\end{array}$ & & & \\
\hline & 20 & 51 & 4 & 17 & 12.0 & $0.16(-0.09,0.40)$ & & $\rightarrow$ \\
\hline Emerick et al., 2009 [13] & 2 & 20 & 1 & 10 & 13.6 & $0.00(-0.23,0.23)$ & & 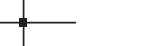 \\
\hline Kao et al., 1994 [16] & 3 & 106 & 9 & 30 & 0.0 & $-0.27(-0.44,-0.10)$ & & \\
\hline Sinclair et al., 2011 [17] & 3 & 30 & 0 & 27 & 47.5 & $0.10(-0.02,0.22)$ & & - \\
\hline Wenig et al., 1989 [10] & 2 & 19 & 0 & 18 & 26.9 & $0.11(-0.06,0.27)$ & & - \\
\hline Total $(95 \% \mathrm{CI})$ & & 120 & & 72 & 100.0 & $0.09(0.01,0.18)$ & & \\
\hline Total events & $27(22$. & $\%)$ & $5(6.9 \%$ & & & & & \\
\hline \multicolumn{7}{|c|}{ Heterogeneity: $\tau^{2}=0.00 ; \chi^{2}=0.97, \mathrm{df}=3(p=0.81) ; I^{2}=0 \%$} & $-0.5-0.25$ & $\begin{array}{lll}1 & 0.25 & 0.5\end{array}$ \\
\hline \multicolumn{6}{|c|}{ Test for overall effect: $\mathrm{Z}=2.21(p=0.03)$} & & Primary & Secondary \\
\hline
\end{tabular}

Fig. 5. Forest plot: leakage around the prosthesis in patients undergoing primary and secondary tracheoesophageal puncture after removal.

compared to the secondary puncture. Regarding this subject, 6 articles analyzed the TEP, and the incidence of fistulas was not configured as a risk factor ( $p=0.69$ and $\left.I^{2}=86 \%\right)$. When studies that led to high heterogeneity were removed $[13,15]$, we observed the same effect obtained above ( $p=0.48$ and $I^{2}=20$; Fig. 6 ).

\section{Discussion}

Boscolo-Rizzo et al. [14] reported that TEP1 and TEP2 were equally safe and effective in speech rehabilitation. However, Maniglia et al. [11] showed that TEP1 is associated with an increase in complication rates in relation to TEP2, though the number of patients was smaller in TEP2. Lacau St Guily et al. [5] reported an increased risk of pharyngocutaneous fistula (PCF) in primary TEP compared to secondary TEP followed by chemoradiotherapy, though with no statistical significance in speech rehabilitation. Results found by other studies showed 
Barauna Neto et al.: Comparison between Primary and Secondary Tracheoesophageal Puncture Prosthesis: A Systematic Review

\begin{tabular}{|c|c|c|c|c|c|c|c|c|}
\hline \multirow{3}{*}{$\begin{array}{l}\text { Study or subgroup } \\
\text { Boscolo-Rizzo et al., } 2008 \text { [14] }\end{array}$} & \multicolumn{2}{|l|}{ TEP } & \multicolumn{3}{|l|}{ No TEP } & \multirow{2}{*}{$\begin{array}{l}\text { Risk difference } \\
\text { M-H, fixed, } \\
95 \% \text { CI }\end{array}$} & \multirow{2}{*}{\multicolumn{2}{|c|}{$\begin{array}{l}\text { Risk difference } \\
\text { M-H, fixed, } \\
95 \% \text { CI }\end{array}$}} \\
\hline & events & total & events & total & $\begin{array}{l}\text { weight, } \\
\%\end{array}$ & & & \\
\hline & 21 & 67 & 26 & 119 & 23.5 & $0.09(-0.04,0.23)$ & & - \\
\hline Emerick et al., 2009 [13] & 10 & 20 & 0 & 10 & 3.6 & $0.50(0.25,0.75)$ & & \\
\hline Karlen and Maisel, 2001, [15] & 0 & 33 & 14 & 63 & 11.9 & $-0.22(-0.33,-0.11)$ & $\rightarrow-$ & \\
\hline Markou et al., 2004 [18] & 10 & 55 & 39 & 322 & 25.7 & $0.06(-0.05,0.17)$ & & - \\
\hline Mäkitie et al., 2006 [19] & 14 & 72 & 7 & 36 & 13.1 & $0.00(-0.16,0.16)$ & - & \\
\hline Sayles et al., 2013 [21] & 19 & 73 & 31 & 91 & 22.2 & $-0.08(-0.22,0.06)$ & $\rightarrow$ & \\
\hline Total $(95 \% \mathrm{CI})$ & & 320 & & 641 & 100.0 & $0.01(-0.05,0.07)$ & & \\
\hline Total events & 74 & & 117 & & & & & \\
\hline \multicolumn{7}{|c|}{ Heterogeneity: $\chi^{2}=36.32, \mathrm{df}=5(p<0.00001) ; I^{2}=86 \%$} & $-0.5-0.250$ & 0.250 .5 \\
\hline \multicolumn{7}{|c|}{ Test for overall effect: $\mathrm{Z}=0.40(p=0.69)$} & TEP & No TEP \\
\hline
\end{tabular}

Fig. 6. Forest plot: the impact of the creation of tracheoesophageal fistula in the formation of pharyngocutaneous fistula.

that complications of tracheostomy, dehiscence, stenosis and leakage around the prosthesis are uncommon, regardless of the type of puncture (primary or secondary [7, 13, 17]).

As for wound infection, there was a higher occurrence in patients undergoing primary TEP, but with no statistical significance when compared to secondary TEP (Fig. 2). A higher number of infections in TEP1 patients was shown; however, there was no statistical significance. Furthermore, this is a complication easily resolved with no surgical intervention [14]. Emerick et al. [13] found no difference in their series as regards infection among groups and this is very similar to data found by others [9-11], with slightly higher numbers of infection in the surgical wound in TEP1 when compared to TEP2, however, with no statistical significance. In contrast, Shenoy et al. [12] found no occurrence of wound infection in their series.

The occurrence of stenosis was very similar in both groups, with a high occurrence in TEP1, but without statistical significance (Fig. 3). Despite the different ways the articles were analyzed, with some heterogeneity, this complication needs more attention, with a new procedure for expansion of tracheostomy in 1 patient [10] among the 24 who had stenosis in the meta-analysis. It was not reported if the patient had received primary or secondary TEP. The articles that investigated this complication reported a low occurrence. Emerick et al. [13] who were actively researching such occurrences in their series did not report any findings.

Leakage around the prosthesis is the most common problem associated with maintenance of the TEP and also the most common indication for the exchange of the prosthesis. The inefficiency of the prosthesis is normally caused by deposition of Candida albicans and this is the most important factor in determining its useful life. The negative pressure in the esophagus during the swallowing process is also recognized as an overflow factor around the prosthesis [22]. Both primary and secondary TEP had very similar leakage rates around the prosthesis and, in most cases, this was treated by replacing the prosthesis with another of a different size (Fig. 4). In our analysis, one study [16] showed high heterogeneity and was removed from the analysis. Thus, it showed a reduction of $10 \%$ in the risk of leakage in patients submitted to secondary TEP (95\% CI 0.01-0.18; $p=0.03, I^{2}=0 \%$; NNT $\left.=10\right)$, with statistical significance.

There is still controversy as to the appropriate time for the procedure in order to avoid complications, with $50 \%$ PCF in the primary prosthesis group, compared to $0 \%$ in the secondary group [13]. Concern for patients undergoing primary prosthesis is the surgical 
dissection along the tracheoesophageal wall, which may predispose them to impaired closing level of the lower pharyngeal closure and prosthetic fistula of the site. In addition, factors that affect the healing process, such as previous radiation therapy, may increase the incidence of PCF associated with primary prosthesis [23]. Other authors found no significant difference in increased incidence of PCF in patients undergoing primary prosthesis [15, 18, 24, 25]. This meta-analysis showed no disadvantage in prosthesis placement at the same time as the total laryngectomy, when compared to the patients in whom this approach was not used.

The goal of the tracheoesophageal prosthesis rehabilitation is to provide a voice and fluent speech, thus restoring the ability of the patient to communicate verbally. For this purpose, the prosthesis is currently considered the gold standard and preferred method for the rehabilitation of alaryngeal communicability. Much of the debate about the making of a fistula for the passage of a primary or secondary surgical prosthesis has focused on aspects related to voice and not on complication rates.

Although other studies present higher speech rehabilitation success rates for TEP1 [26], this finding can be explained by the lower number of patients who underwent TEP2 and it is also possible that the immediate rehabilitation in TEP1 exerts a positive psychological impact, as suggested by Boscolo-Rizzo et al. [20], motivating patients to intensify the search for oral communication. By contrast, the prolonged absence of the larynx in TEP2 leads to alteration of the esophageal muscles of these patients, who do not need airway protection anymore. This can be a limiting factor in rehabilitation in TEP2. In addition, these patients commonly develop other adaptive speech engines such as pharyngeal phonation, which can disturb the subsequent speech rehabilitation with TEP and voice prosthesis [8].

This study identified a $10 \%$ reduction in the risk of leakage around the fistula in the group undergoing secondary puncture. This result is not only statistically significant, but also accurate since the number of patients included in the analysis was sufficient to establish a definitive result. The sample calculation for this outcome is estimated based on the $15.6 \%$ difference found between the primary and secondary puncture groups (22.5 vs. $6.9 \%)$ and considering a $p<0.05$ and a power of $80 \%$; the minimum number for this conclusion would be 80 patients in each study branch, in the case of a single randomized controlled trial. For the two other outcomes, infection and stenosis, the sample calculation based on the same parameters that would be required shows 351 ( 9.1 vs. 3.9\%) and 594 patients ( 8.5 vs. $4.5 \%$ ), respectively, in each group. Thus, there is a tendency towards lower rates of infection and tracheostomy stenosis in patients undergoing secondary puncture, but the results presented here are not final yet because of the low number of individuals in each analysis.

\section{Conclusion}

This systematic review concluded that there is a reduced risk of leakage around the prosthesis of about $10 \%$ in patients undergoing secondary TEP. There was no statistically significant difference in relation to other studies and the assessment of voice quality.

\section{Disclosure Statement}

The authors declare that they have no conflicts of interest. 
Barauna Neto et al.: Comparison between Primary and Secondary Tracheoesophageal Puncture Prosthesis: A Systematic Review

\section{References}

1 Van Weissenbruch R, Albers FWJ: Vocal rehabilitation after total laryngectomy using the Provox voice prosthesis. Clin Otolaryngol 1993;18:359-364.

2 Singer MI, Blom ED: An endoscopic technique for restoration of voice after laryngectomy. Ann Otol Rhinol Laryngol 1980;89:529-533.

3 Singer MI, Blom ED, Hamaqker RC: Voice rehabilitation after total laryngectomy. J Otolaryngol 1983;12:329334.

4 Panje WR: Prosthetic vocal rehabilitation following laryngectomy - the voice button. Ann Otol Rhinol Laryngol 1981;90:116-120.

5 Lacau St Guily JL, Angelard B, El-Bez M, Julien N, Debry C, Fichaux P, Gondret R: Postlaryngectomy voice restoration. Arch Otolaryngol Head Neck Surg 1992;118:352-355.

6 Chone CT, Gripp FM, Spina AL, Crespo AN: Primary versus secondary tracheoesophageal puncture for speech rehabilitation in total laryngectomy: long-term results with indwelling voice prosthesis. Otolaryngol Head Neck Surg 2005;133:89-93.

7 Cheng E, Ho M, Ganz C, Shaha A, Boyle JO, Singh B, Wong RJ, Patel S, Shah H, Branski RC, Kraus DH: Outcomes of primary and secondary tracheoesophageal puncture: a 16-year retrospective analysis. Ear Nose Throat J 2006;85:262-267.

8 Guttman D, Mizrachi A, Hadar T, Bachar G, Hamzani Y, Marx S, Shvero J: Post-laryngectomy voice rehabilitation: comparison of primary and secondary tracheoesophageal puncture. Isr Med Assoc J 2013;15:565-567.

9 Morrison MD, Ogrady M: Primary tracheo-esophageal puncture voice restoration with laryngectomy. J Otolaryngol 1986;15:69-73.

10 Wenig BL, Mullooly V, Levy J, Abramson AL: Voice restoration following laryngectomy: the role of primary versus secondary tracheoesophageal puncture. Ann Otol Rhinol Laryngol 1989;98:70-73.

11 Maniglia AJ, Lundy DS, Casiano RC, Swim SC: Speech restoration and complications of primary versus secondary tracheoesophageal puncture following total laryngectomy. Laryngoscope 1989;99:489-491.

12 Shenoy AM, Ashok H, Premalata BS, Prasad AVS, Nanjundappa K, Kumar S: Surgical speech restoration by tracheo-oesophageal puncture - Kidwai experience. Indian J Cancer 2000;37:27-31.

13 Emerick KS, Tomycz L, Bradford CR, Lyden TH, Chepeha DB, Wolf GT, Teknos TN: Primary versus secondary tracheoesophageal puncture in salvage total laryngectomy following chemoradiation. Otolaryngol Head Neck Surg 2009;140:386-390.

14 Boscolo-Rizzo P, Zanetti F, Carpené S, Da Mosto MC: Long-term results with tracheoesophageal voice prosthesis: primary versus secondary TEP. Eur Arch Otorhinolaryngol 2008;265:73-77.

15 Karlen RG, Maisel RH: Does primary tracheoesophageal puncture reduce complications after laryngectomy and improve patient communication? Am J Otolaryngol 2001;22:324-328.

16 Kao WW, Mohr RM, Kimmel CA, Getch C, Silverman C: The outcome and techniques of primary and secondary tracheoesophageal puncture. Arch Otolaryngol Head Neck Surg 1994;120:301-307.

17 Sinclair CF, Rosenthal EL, McColloch NL, Magnuson JS, Desmond RA, Peters GE, Carroll WR: Primary versus delayed tracheoesophageal puncture for laryngopharyngectomy with free flap reconstruction. Laryngoscope 2011;121:1436-1440.

18 Markou KD, Vlachtsis KC, Nikolaou AC, Petridis DG, Kouloulas AI, Daniilidis IC: Incidence and predisposing factors of pharyngocutaneous fistula formation after total laryngectomy. Is there a relationship with tumor recurrence? Eur Arch Otorhinolaryngol 2004;261:61-67.

19 Mäkitie AA, Niemensivu R, Hero M, Keski-Säntti H, Bäck L, Kajanti M, Lehtonen H, Atula T: Pharyngocutaneous fistula following total laryngectomy: a single institution's 10-year experience. Eur Arch Otorhinolaryngol 2006;263:1127-1130.

20 Boscolo-Rizzo P, De Cillis G, Marchiori C, Carpenè S, Da Mosto MC: Multivariate analysis of risk factors for pharyngocutaneous fistula after total laryngectomy. Eur Arch Otorhinolaryngol 2008;265:929-936.

21 Sayles M, Koonce SL, Harrison L, Beasley N, McRae AR, Grant DG: Pharyngo-cutaneous fistula complicating laryngectomy in the chemo-radiotherapy organ-preservation epoch. Eur Arch Otorhinolaryngol 2014;271: 1765-1769.

22 Bozec A, Poissonnet G, Chamorey E, Demard F, Santini J, Peyrade F, Ortholan C, Benezery K, Thariat J, Sudaka A, Anselme K, Adrey B, Giacchero P, Dassonville O: Results of vocal rehabilitation using tracheoesophageal voice prosthesis after total laryngectomy and their predictive factors. Eur Arch Otorhinolaryngol 2010;267: 751-758.

23 Dowthwaite SA, Penhearow J, Szeto C, Nichols A, Franklin J, Fung K, Yoo J: Postlaryngectomy pharyngocutaneous fistula: determining the risk of preoperative tracheostomy and primary tracheoesophageal puncture. J Otolaryngol Head Neck Surg 2012;41:169-175.

24 Parikh SR, Irish JC, Curran AJ, Gullane PJ, Brown DH, Rotstein LE: Pharyngocutaneous fistulae in laryngectomy patients: the Toronto Hospital experience. J Otolaryngol 1998;27:136-140.

25 Gonçalves AJ, de Souza JA, Menezes MB, Kavabata NK, Suehara AB, Lehn CN: Pharyngocutaneous fistulae following total laryngectomy comparison between manual and mechanical sutures. Eur Arch Otorhinolaryngol 2009;266:1793-1798.

26 Deschler DG, Bunting GW, Lin DT, Emerick K, Rocco J: Evaluation of voice prosthesis placement at the time of primary tracheoesophageal puncture with total laryngectomy. Laryngoscope 2009;119:1353-1357. 